\title{
Etnografía de una organización de estudiantes indígenas en la amazonía peruana: las ambivalencias de la protesta*
}

\author{
Doris Buu-Sao \\ Sciences Po-Paris
}

\section{Resumen}

La etnografía de una organización estudiantil indígena con sede en Iquitos, la ciudad más grande de la Amazonía peruana, permite examinar la experiencia de sus líderes. Sobre la base de las habilidades adquiridas a través del contacto con las escuelas y las organizaciones activistas, estos nuevos líderes se afirman a través de movilizaciones cada vez más visibles. El proceso de politización a través del cual los estudiantes aprenden a exigir sus derechos a causa de una identidad indígena se examina desde el punto de vista de su lugar en espacios urbanos de activismo. Es en tales espacios donde se desarrollan las definiciones de liderazgo indígena. Estos entran en conflicto con otras organizaciones más tradicionales y contribuyen a las tensiones internas dentro del "movimiento de los pueblos indígenas". Las redes de mediación en las que participan los estudiantes indígenas, redes que sirven como conductos para los mensajes que las autoridades locales, los activistas ecológicos y las compañías petroleras desean transmitir a las comunidades indígenas, subrayan la ambivalencia de este movimiento de protesta.

Palabras claves: jóvenes indígenas, gobernanza, movimientos sociales, conflictos sociales, gestión de recursos, Cuatro Cuencas, Perupetro.

\footnotetext{
Abstract

The ethnography of an indigenous student organization based in Iquitos, the largest town in Peruvian Amazonia, allows one to examine the experience of its leaders. On the basis of skills acquired through contact with schools and activist organizations, these new leaders are asserting themselves via ever more

* Este artículo fue escrito originalmente en francés y apareció en el año 2012 dentro de la revista Critique internationale, no 57,(4), 37-52. Se puede consultar la versión electrónica del artículo en el siguiente enlace: https:/www.cairn.info/revuecritique-internationale-2012-4-page-37.htm.
} 
visible mobilizations. The process of politicization through which students learn to demand their rights on account of an indigenous identity is examined from the point of view of their place in urban spaces of activism. It is in such spaces that definitions of indigenous leadership are developed. These come into conflict with other, more traditional, organizations and contribute to internal tensions within the "indigenous people's movement." The networks of mediation in which indigenous students participate - networks that serve as conduits for the messages that local authorities, ecological activists, and oil companies wish to pass on to indigenous communities - underscore the ambivalence of this protest movement.

Key words: indigenous youth, governance, social movements, social conflicts, resource management, Cuatro Cuencas, Perupetro.

Bagua, 5 de junio de 2009. En nombre de sus derechos y su identidad, las poblaciones "indígenas" 1 de la región de Amazonas protestan contra los decretos que permitirían a empresas privadas la extracción de hidrocarburos en sus territorios. La intervención de la policía para despejar una carretera bloqueada durante dos meses ocasiona nueve víctimas entre los manifestantes. En represalia, 25 policías son tomados como rehenes y ejecutados (Hughes, 2010). La Asociación Interétnica para el Desarrollo de la Selva Amazónica (Aidesep; en adelante, la Asociación) desempeña un papel clave en esta movilización. Establecida desde 1980 en diferentes niveles del territorio (comunidad nativa ${ }^{2}$, distrito, departamento), representa más del $90 \%$ de los 332000 de indígenas censados en 2007 en la Amazonía peruana 3 .

1 "Indígena” es el término más utilizado en Perú, y lo usaremos aquí, a pesar de sus connotaciones en el idioma francés.

2 Las comunidades nativas tienen personalidad jurídica, que el estado les otorga sobre la base de criterios precisos: especificidades lingüísticas, culturales y sociales, posesión común del mismo territorio en el que vive la comunidad de manera nuclear o dispersa. Decretos Ley No. 20653 de 1974 y No. 22175 de 1978.

3 En 2007, el Instituto Nacional de Estadística e Informática (INEI) dedicó por primera vez un censo específico a los nativos, de acuerdo con los mismos criterios que a comunidades nativas. INEI, II Censo de las comunidades indigenas de la Amazonía peruana, Lima, Instituto Nacional de Estadistica e Informática, 2008. 
Después de los eventos en Bagua, varios líderes de la Asociación fueron procesados, y su presidente, Alberto Pizango, se vio obligado a exiliarse en Nicaragua. La prensa francesa, para resumir este episodio de oposición frontal entre manifestantes y policías, lo tituló "Golpe sangriento. Los indios del Perú vuelven a la guerra” (Despic-Popovic, 2009). El 23 de junio de 2010, me encontré con Raúl ${ }^{4}$ en Iquitos. Este estudiante de 22 años del grupo étnico Achuar ha sido miembro de la Organización de Estudiantes de los Pueblos Indígenas de la Amazonía Peruana (en adelante, Oepiap o la Organización), con sede en Iquitos, durante los últimos tres años. Raúl se ha movilizado varias veces contra las diferentes compañías petroleras que operan en su región de origen. Durante los eventos del 5 de junio de 2009, en Bagua, hizo campaña junto a Willem, entonces presidente de la Organización y jefe del comité de lucha indígena de Iquitos. En el momento de la entrevista, me dijo que un representante de una compañía petrolera lo contactó, unos meses antes, para pedirle que animara a las autoridades de su comunidad nativa a negociar con la compañía, y reconoció que luego "engañó a su pueblo": "Me dijeron que me presentara como parte del gobierno regional. Yo acepté [...] llegué y les dije soy del gobierno regional. Pero en realidad, yo era de la compañia petrolera [...] convencí a dos Apus ${ }^{5}$ y los llevé conmigo a Lima"'. Los Apus finalmente permiten a la compañía expandir su actividad a la porción del lote petrolero en el que viven; hoy la empresa contribuye con una porción decisiva al presupuesto de la Organización.

Bagua e Iquitos, enfrentamientos y arreglos: la confrontación de estas dos historias invita a considerar la complejidad de la protesta indígena, imposible de ser resumida a las prácticas de "guerra" visibles

Sobre la representatividad de la Asociación, ver Jorge Dandler, Pueblos indígenas de la Amazonía peruana y desarrollo sostenible, Lima, OIT / Oficina de Área y Equipo Técnico Multidisciplinario para los países del área andina, 1998.

4 Todos los nombres de encuestados son seudónimos.

5 Término quechua que se refiere a los jefes tradicionales en varios grupos étnicos amazónicos.

6 Entrevista con Raúl, estudiante de enfermería, 22 años. Iquitos, 23 de junio de 2010. 
en los momentos de efervescencia. La Oepiap es un terreno ideal para restaurar las múltiples voces de este desafío, en el que las interacciones no son solo de confrontación y deben analizarse en términos de espacio en el que encajan. Iquitos, poblado por 380000 habitantes, es la capital de Loreto, una región amazónica que se extiende sobre el tercio nororiental del territorio nacional. Con el 39,5\% de la población nativa que vive en ese espacio, esta provincia concentra la mayor diversidad étnica del país. Alrededor de una cuarta parte de su área está cubierta por concesiones petroleras operativas ${ }^{7}$ y la mayoría de los otros lotes está en negociación, lo que causa conflictos regulares con las comunidades nativas, cuyas tierras están precisamente en los lotes en cuestión. A veces, son necesarios varios días de navegación para llegar a las comunidades nativas, pues la red de carreteras está muy poco desarrollada en la región, a pesar del esfuerzo sostenido, a lo largo de la historia del Perú, para "domesticar" esta "frontera oriental" (Barclay \& Santos-Granero, 2002). Jóvenes nativos acuden cada vez más a la ciudad para estudiar y juegan un papel crucial en la evolución de las políticas de etnicidad (Espinosa de Rivero, 2009: 56). Registrados en la universidad pública, a menudo se unen a asociaciones de estudiantes indígenas, como la Oepiap que cuenta con unos cincuenta miembros. Todos provienen de las comunidades nativas de Loreto y coexisten en Iquitos desde la creación de la Organización en 2003. Sobre la base de un análisis de las sociabilidades, las interacciones y las trayectorias en las que se inscriben estos jóvenes de la Oepiap, buscaremos poner en relieve la complejidad de la disputa nativa, que no puede reducirse a una oposición binaria entre la dominación y la resistencia ${ }^{8}$.

7 Estimado a partir del mapa de los lotes otorgados por la agencia pública de promoción de la extracción de petróleo, Perúpetro, 2010.

8 Este estudio se basa en dos encuestas etnográficas realizadas entre junio y julio de 2010 y entre enero y abril de 2011, respectivamente. Las encuestas dieron lugar a entrevistas con 15 miembros de la Organización, a la distribución de un cuestionario a 40 de sus miembros, y a la observación de la vida cotidiana de la Organización y el examen de archivos (Oepiap, otras organizaciones militantes, medios de comunicación y policía). Este trabajo se completó con un regreso al campo en 2012 para restaurar la memoria de esta encuesta a los estudiantes. 


\section{La politización de una "juventud indígena”}

La creación de organizaciones estudiantiles indígenas 9 está fuertemente vinculada al aumento de la escolarización de las poblaciones indígenas. De hecho, la multiplicación de los programas de capacitación para maestros bilingües en la Amazonía peruana desde la década de 1940, primero por iniciativa de organizaciones evangélicas o católicas en cooperación con el Ministerio de Educación y, luego, en el contexto de proyectos de desarrollo de Aidesep, ha resultado en una mayor alfabetización entre estas poblaciones ${ }^{10}$. La Asociación también aprobó una serie de acuerdos con universidades públicas para promover el acceso indígena a la educación superior.

\section{Entre subsistencia y distinción}

Sin embargo, los jóvenes indígenas que ingresan a la universidad enfrentan condiciones de vida muy difíciles. Están lejos de su comunidad nativa y tienen presupuestos extremadamente bajos, poco dominio del espańol y un nivel mucho más bajo de educación general. Muchos de ellos abandonan sus estudios antes de finalizarlos (Espinosa de Rivero, 2008). Fue en 2002 que una primera generación de estudiantes de comunidades nativas ingresó a la Universidad Nacional de la Amazonía Peruana (UNAP) de Iquitos, la principal institución pública en la región de Loreto con la que Aidesep acababa de firmar un acuerdo. Aunque son albergados en las instalaciones de la Asociación, estos nuevos estudiantes deben luchar para hacer frente a los gastos universitarios y alimenticios. La preocupación individual por la subsistencia encuentra entonces su solución en la organización colectiva: en los registros del distrito el 12 de diciembre de 2003, formalmente, la misión oficial de la Oepiap es "administrar las donaciones de instituciones públicas y privadas, nacionales como extranjeros [...] para subsidiar los gastos

9 También hay asociaciones en Lima, Pucallpa y Cusco.

10 En 1993, el $49 \%$ de los hablantes de lenguas indígenas no sabían leer ni escribir; en 2007, fue el $38 \%$. Para las personas cuya lengua materna es el español, los resultados fueron del $15 \%$ para 1993 y del $14 \%$ para 2007 (INEI, IX Censo de población y vivienda, Lima, INEI, 1993, INEI, II Censo de las comunidades indígenas de la Amazonía peruana, citado). 
de estudios universitarios de estudiantes de la Amazonía peruana" ${ }^{11}$. Por lo tanto, incluso si está relacionada con las federaciones locales y regionales de Aidesep, la Oepiap no tiene la intención, inicialmente, de representar los intereses colectivos de las comunidades nativas. La situación de estos estudiantes atestigua la naturaleza ambivalente de la "juventud nativa", cuya transición a la edad adulta ahora está marcada por el camino educativo y ya no por los "ritos de iniciación" (Poirier, 2009: 22). De hecho, aunque aparecen en relación con sus compañeros de clase universitarios como los más pobres en capital cultural, económico y social, estos jóvenes indígenas generalmente provienen de los grupos más influyentes de su medio de origen. De los 40 estudiantes encuestados en 2011, 36 dijeron tener en su familia, un maestro, un líder ${ }^{12}$ y/o una persona que ejercen un mandato político local (generalmente, alcalde, teniente de alcalde o juez de paz $)^{13}$. Por lo tanto, están vinculados a redes de influencia política y su proximidad a los líderes de las federaciones locales de Aidesep les permite dominar la información necesaria para ingresar a la universidad. En la mayoría de casos, son hombres que aparecen como dominantes entre los dominados. Los lazos de parentesco, la afiliación a federaciones y redes de afinidades interétnicas de los colegios misioneros a los que ha asistido la mayoría de los miembros de la Oepiap son igualmente decisivos para conocer la existencia de la Organización y solicitar integrarse a ella para beneficiarse del alojamiento y de la comida.

\section{La afirmación de un colectivo de "guerreros" que compite con la Aidesep}

En el año 2006, los jóvenes indígenas hacían cola todos los días en el refectorio de la universidad con la esperanza de poder alimentarse con lo que quedaba, una vez que todos los estudiantes registrados recibieran

11 Artículo 4 de los estatutos de Oepiap.

12 Este término generalmente se refiere a un presidente de una organización indígena, ya sea local o regional.

13 Estos "jueces de paz" son elegidos a nivel local de acuerdo con su prestigio. La mayoría de las veces no cuentan con capacitación legal e intervienen principalmente en los casos de delitos menores. 
servicios. El acceso al refectorio está reservado para estudiantes con más de 12 de nota de promedio, resultado que rara vez obtienen los estudiantes nativos. Entonces, se hicieron notar por un miembro de Juventudes Socialistas (JS, en adelante), afiliado al Partido Socialista de los Trabajadores (PST, en adelante), de obediencia trotskista. Los cuadros iquiteños del partido, ya debilitados por el colapso de la izquierda radical en Perú, encuentran, en la ayuda a la organización de estudiantes indígenas, una forma de sobrevivir en el escenario militante ${ }^{14}$. El 22 de mayo de 2006, la Oepiap y el JS deciden juntos ocupar el rectorado. El personal administrativo es retenido como rehén durante un día. Los ocupantes, que usan "pinturas de guerra" 15 en el torso y la cara, dibujan consignas en las paredes, como "¡Viva la lucha indígena!"16. Obtienen un derecho específico de acceso al refectorio, subsidiado por el Consejo Regional de Loreto. Esta acción subversiva fortalece los vínculos entre JS y la Oepiap. Los dos presidentes de la Organización que se suceden entre 2006 y 2010 integran el colectivo trotskista con un puñado de estudiantes nativos afiliados. Los nuevos reclutas participan en los talleres de capacitación y lectura de JS, que aprovechan la oportunidad de un caso de corrupción relacionado con la gestión de la universidad en 2006 para aumentar el número de sus activistas y garantizar su supervivencia política. Los nativos trotskistas adquieren nuevas habilidades en el arte de expresar ideas, escribir discursos y organizar demostraciones y debido a que ocupan puestos de autoridad dentro de la Oepiap, su experiencia

14 Fundado en 1971, el PST es una de las seis fracciones trotskistas nacidas de la "nueva izquierda" insurreccional de los ańos sesenta (Ricardo Letts, La izquierda peruana, organizaciones y tendencias, Lima, Mosca Azul Editores, 1981). Al igual que otras organizaciones marxistas, el partido sufrió la descalificación de la izquierda por la persecución de Sendero Luminoso. El número de sus activistas (50) y simpatizantes (200) da testimonio de su debilidad actual (estimación proporcionada por uno de los últimos ejecutivos del PST residente en Iquitos, conversación informal del 26 de junio de 2012, Lima).

15 Los términos "pinturas de guerra" y "bailes de guerra" son utilizados repetidamente por los medios locales (en particular, el periódico La Región), que parecen ser particularmente atractivos en la dimensión "auténticamente" indígena de estos jóvenes movilizados en un entorno urbano.

16 Según las fotografías de los lugares después de la ocupación del rectorado. Archivo personal de un activista del PST. 
influye en los debates internos en la Organización. Las agendas de las reuniones semanales reflejan una politización, si se entiende esto como el aumento de la generalidad de los discursos y la afirmación de la conflictividad de las posiciones adoptadas (Hamidi, 2006); por ejemplo, se menciona la creación de una "comisión de propaganda", un análisis político del gobierno o un "plan de lucha" de la Organización ${ }^{17}$. La estructuración de estas prácticas forma parte de una red de organizaciones movilizadas localmente. Los estudiantes también se manifiestan junto con el capítulo local de la Confederación General de Trabajadores del Perú (CGTP), el principal sindicato del país, y las ONG movilizadas por temas ambientales. La creciente alianza con estas ONG ambientalistas, que disfrutan de más recursos materiales que el PST, favorece la difusión de una representación del nativo como un "salvaje ecológicamente noble" (Redford, 1990). Aidesep, para la cual la participación en redes de activismo urbano corrompe a los nativos, critica a la Oepiap y le retira su apoyo. En 2009, los estudiantes indígenas encontraron un lugar en las instalaciones de una ONG ambiental "aliada", la Red Ambiental de Loreto (RAL). Las raíces indígenas son exaltadas e incluso recordadas a los estudiantes diariamente por la ubicación de este espacio, en las afueras de la ciudad, con una exuberante vegetación, casas sobre pilotes y locales dedicados a prácticas rituales, similares a una comunidad nativa.

La combinación de estas diferentes influencias se traduce en una puesta en escena quelos estudiantes de la Organización reproducen durante sus movilizaciones, ya sea que estén dirigidas contra la administración regional, las compañías petroleras, las autoridades universitarias o la política del gobierno nacional. La mayoría de las veces, ocupan un local, organizan un evento o incluso organizan piquetes o bloqueos en la calle, prácticas relativamente violentas, ya que cualquier vehículo que se aventura en la ciudad cuando se declara un piquete, se expone a un alboroto punitivo (neumáticos quemados, carrocería destruida, ventanas rotas...). Durante estos eventos, los estudiantes, generalmente vestidos con jeans y camisetas, desfilan con sus pechos desnudos, el cuerpo y la cara cubiertos de "pinturas de guerra", llevando las coronas de plumas

17 Libro de reuniones de Oepiap, actualizado desde 2004 (obligatorio para cualquier asociación registrada formalmente). 
y las joyas de las autoridades tradicionales, cantando sus consignas enérgicamente. A veces, terminan su intervención con un "baile de guerra": dos manifestantes se enfrentan, se desafían en su idioma nativo imitando golpes de palos y saltando en el sitio al ritmo de sus gritos.

La ambivalencia de la categoría indígena, recurso decisivo de movilización, se refleja en la forma en que Guillermo responde a la pregunta que se le hace sobre su origen nativo. Hijo de misioneros, nacido en la ciudad de Yurimaguas, Guillermo se fue a la edad de 7 años a vivir con sus padres en la comunidad de Balsapuerto, del grupo étnico Shawi: "En algunos casos sí, en otros digo que no. Aqui, en la organización, digo 'isi, de verdad!', bien, no naci en la comunidad de Balsapuerto y el shawi no es mi lengua materna, ipero lo hablo! Pero en la universidad, si me preguntas, te digo que naci en la ciudad de Yurimaguas. [...] Porque en la universidad, la mayoría son mestizos, ¿verdad? Tienen poco interés en el movimiento indigena" 18 . Este discurso da testimonio de la plasticidad del uso de la etnicidad, que se activa solo cuando despierta un interés que permite a los estudiantes mejorar su condición. Guillermo es indígena cuando se trata de movilizar o justificar su admisión a la Oepiap; en otras palabras, cuando está en presencia de personas que están "interesadas" en los nativos, pero los criterios de identificación son flexibles. Si bien la condición oficial para pertenecer a la Organización es nacer y haber vivido en una comunidad nativa, Guillermo prefiere presentar su conocimiento del idioma, que aprendió por haber vivido diez años en la comunidad de Balsapuerto. Por otro lado, en la universidad, la etiqueta de "nativo" es más bien un estigma. Guillermo se abstiene de efectivizarla. Prefiere fusionarse con los "mestizos", descendientes de los colonos de la Costa peruana, los Andes e incluso de Europa, considerados como la mayoría de la población de Iquitos. Sin embargo, la teatralización de las "raíces indígenas" de los estudiantes y la frecuencia de sus movilizaciones favorecen la aparición de estos jóvenes en los medios locales. Durante la ola de protestas que comenzó en 2008 y que incluyó los eventos de Bagua en 2009, los líderes de la Oepiap dirigen el Comité de Lucha de

18 Entrevista con Guillermo, 19, estudiante de Agronomía, Iquitos, 16 de febrero de 2011. 
Iquitos y la prensa habla de Willem como el "lider que representa a los grupos étnicos amazónicos en la región" 19.

El grupo de estudiantes logra así reemplazar, localmente, a las autoridades de la red de Aidesep en el momento en que esta se debilita por la acusación judicial contra Pizango tras los eventos de Bagua. En junio de 2010, Pizango, al regresar del exilio, pasa por la ciudad de Yurimaguas. Estuve allí, porque acompañé a Willem en su campaña para las elecciones regionales como candidato de un pequeńo partido local. Nos alojamos en el mismo hotel que Pizango, lo que me permitió ponerme en contacto con los miembros de la Asociación. Mientras un activista del partido de Willem intentó conseguirme una entrevista con el presidente de Aidesep, un amigo de este último intervino y me preguntó sobre mi proyecto. Estaba a cargo del programa de Aidesep para capacitar a profesionales indígenas en salud intercultural y fue muy crítico con la organización cuando supo que conocía a su presidente. Desaprueba la aculturación de estos estudiantes que, sin tener en cuenta la voluntad de los líderes tradicionales de las comunidades, hacen campaña en partidos que hablan del proletariado. En la capacitación que dirige, los estudiantes reciben una beca integral, se dedican únicamente a sus estudios y se comprometen a retornar a su comunidad para practicar su profesión. Obviamente, no apruebo el examen, pues he elegido un objeto ilegítimo para analizar la protesta indígena y, por lo tanto, no estoy invitada a hablar con el presidente de Aidesep ${ }^{20}$. Las dos organizaciones compiten por el monopolio de la representación urbana de las comunidades nativas y se oponen en la definición de "buen nativo". Mientras que Aidesep lo define como preservado de la influencia externa, la Oepiap lo considera un líder abierto a las contribuciones de la militancia "occidental".

\section{“Amistades paradójicas” y redes de mediación}

Los estudiantes indígenas se presentan como miembros influyentes de sus comunidades, discurso transmitido por la prensa cuando los

19 "Garantizamos una protesta pacífica", La Región, 11 de junio de 2009.

20 Diario de campo, Yurimaguas, 30 de junio de 2010. 
describe como los "líderes del movimiento indígena" en Perú. Por lo tanto, están bien ubicados para asegurar la traducción entre la cultura dominante y su entorno familiar.

\section{Intermediarios en los lugares de mediación}

Los estudiantes indígenas tienden a adquirir una nueva legitimidad dentro de sus comunidades, tradicionalmente dominadas por la edad y la autoridad relacionada con los ritos. Luis, presidente de la Oepiap en 2011, habla sobre el día, en el cual, de vuelta a su comunidad, fue designado para presidir una reunión, aunque no se lo había propuesto: "En las reuniones, sabian muy bien que estaba estudiando. Cada vez, durante las vacaciones, iba allí y hablaba con los Apus, con los maestros... Con los líderes, pues"21. Si bien se puede discutir al interior de las comunidades, en cualquier caso, esta legitimidad es esgrimida por los jóvenes nativos, quienes se consideran una élite educada que posee habilidades poco comunes. Según Nay $\&$ Smith, tienen la capacidad de "intervenir en diferentes ámbitos cuyas reglas, procedimientos, conocimientos y representaciones pueden ser significativamente distantes" (2002: 12) y, por lo tanto, pueden operar una intermediación que es a la vez la búsqueda de un compromiso y la construcción de un "sentido común entre entornos institucionales que no utilizan los mismos conocimientos y representaciones" (13).

Sus habilidades como mediadores se solicitan diariamente: son contactados regularmente por las ONG ambientalistas que desean lanzar una campaña de sensibilización entre las comunidades, por partidos políticos locales que buscan votos y por candidatos indígenas ${ }^{22}$ en el contexto de elecciones regionales, e incluso por empresas que buscan entablar un diálogo con las comunidades que se oponen a cualquier actividad extractiva. Luis habla sobre los diferentes viajes que hizo con James, el presidente de la Red Ambiental de Loreto (RAL), a diferentes

21 Entrevista con Luis, 27, estudiante de Ingeniería Ambiental, Iquitos, 17 de febrero del año 2011.

22 Durante la última década, cada lista de candidatos para elecciones regionales en áreas donde las poblaciones indígenas son importantes debe tener una cierta cuota de candidatos indígenas. Ley Electoral No 27683 (2002). 
comunidades nativas: "[Di] una conferencia a los Kukamas sobre temas ambientales. Alli conoci a mucha gente. También fui con James para hacer un taller sobre el medio ambiente en mi comunidad, [...] para dar un taller en idioma. En español ${ }^{23}$ y traducido en idioma. Yo mismo distribui y expliqué el Convenio 169"24. Luis, cuya lengua materna es el awajún, se presenta como un mediador relevante, incluso para otros grupos étnicos distintos del suyo, como los kukamas. Así, la traducción no es solo lingüística: también se trata de transmitir conceptos, como los desarrollados por el Convenio 169 de la Organización Internacional del Trabajo, de un universo social a otro. El conocimiento de las autoridades locales y los procedimientos rituales hacen posible operar esta traducción legítimamente. Los estudiantes nativos transmiten mensajes con diversos grados de contenido, pero los términos de transmisión son similares; la traducción es entonces lingüística, conceptual y procesal.

\begin{tabular}{|l|c|}
\hline \multicolumn{1}{|c|}{ Campos de estudio } & Porcentajes (n=58) \\
\hline $\begin{array}{l}\text { Salud (farmacia, enfermería, medicina) y } \\
\text { educación primaria }\end{array}$ & 27,6 \\
\hline $\begin{array}{l}\text { Medio ambiente (agronomía, ecología, gestión } \\
\text { ambiental, biología) }\end{array}$ & 27,6 \\
\hline $\begin{array}{l}\text { Industria (alimentación, electrónica, } \\
\text { informática, ingeniería química...) }\end{array}$ & 20,7 \\
\hline $\begin{array}{l}\text { Administración, comercio internacional, } \\
\text { contabilidad }\end{array}$ & 12,1 \\
\hline $\begin{array}{l}\text { Artes, letras y ciencias humanas (antropología, } \\
\text { derecho, filosofía) }\end{array}$ & 12,1 \\
\hline & $100,01^{*}$ \\
\hline
\end{tabular}

* Porcentajes redondeados al decil superior.

Fuente: registros informáticos de la Oepiap, consultados en Iquitos el 24 de marzo de 2011.

$23 \mathrm{Al}$ referirse a su lengua materna, los estudiantes hablan de "idioma", sin agregar necesariamente el calificativo "indígena".

24 Entrevista con Luis, citada. 
Las tres cuartas partes de los miembros de la Organización han sido capacitados en tecnologías sanitarias, ambientales e industriales; es decir, áreas consideradas "compatibles" con su estatus indígena y, sobre todo menos selectivas, aunque la mayoría de ellos se encuentra en la parte inferior de la jerarquía de disciplinas, que van desde las más técnicas hasta las más abstractas y exigentes en términos de fluidez en español. Sin embargo, aprenden habilidades específicas que les permiten traducir mensajes que sus interlocutores quieren entregar a las comunidades nativas. Luis no solo traduce mensajes de las ONG ambientalistas: en varias ocasiones, medió entre los representantes de las comunidades en su distrito y una compañía petrolera que quería operar en su región.

\section{La legitimación de los intercambios materiales en términos de amistad}

Las entrevistas que realicé resaltan la existencia, desde 2009, de una multiplicidad de alianzas individuales entre estudiantes en busca de ingresos y de compañías petroleras de la región. Incluso, sucede que los primeros ofrecen a estas sus servicios, como traductores o negociadores con sus comunidades de origen, sin solicitar remuneración. Estas alianzas a veces fracasan por su falta de transparencia: un estudiante fue expulsado de la Organización; otro, privado de su cargo como presidente. Evocan las "transacciones colusorias", definidas por Michel Dobry como "intercambios entre actores ubicados en diferentes sectores o campos y autónomos, [... cada uno involucrado en temas especificos en los sectores sociales en los que están inmersos" (2002: 111). Ciertamente, los actores que no participan en el intercambio los calificarán como ilegítimos, pero de todos modos producen legitimidad, porque van acompańados de un reconocimiento mutuo de los sectores involucrados en la transacción. Veamos un ejemplo de lo que aparece en el análisis de la formación de una transacción colusoria observada en el campo.

Iquitos, 5 de marzo de 2011. La visita de Jorge, ingeniero de una compañía petrolera, se anuncia durante la asamblea general semanal del domingo por la mañana. Todo el grupo espera pacientemente en la sala de reuniones, cuando llega Jorge, precedido por estudiantes que llevan cajas. Willem lo presenta como un "amigo de toda la vida", se abrazan, bromean 
sobre su "público" y hablan entre ellos. Después de abrir las cajas, llenas de una impresionante cantidad de utensilios de cocina que el ingeniero ofrece personalmente a la Organización, una docena de estudiantes se levanta y todos vienen a presentarse y agradecer a Jorge. Este último habla durante casi una hora. Él afirma que conocía a la familia de Willem desde hace más de quince años, cuando trabajaba como ingeniero en una base de explotación petrolera de su empresa, cerca de la comunidad nativa del joven indígena. Cuenta una serie de anécdotas para poner énfasis en la frugalidad de su experiencia de la vida cotidiana nativa (dormir en el suelo, arriesgarse a contraer la rabia debido a los murciélagos...) y alienta a los jóvenes nativos a mantener esta humildad de su entorno familiar y a aceptar a la vez la ayuda de extraños. La reunión dura más de dos horas ${ }^{25}$. Posteriormente, Willem me cuenta que había conocido a Jorge durante las movilizaciones de 2008 a 2009, cuando era presidente de la Oepiap y del comité de lucha de Iquitos; el ingeniero lo había llamado y quería conocerlo. Desde entonces, se han visto regularmente; incluso, Jorge lo ayudó a financiar su campańa electoral.

Willem se refiere a Jorge como un "amigo" 26 . En las relaciones de clientelaje, el término 'amistad' es frecuente, pues al presentar "bajo el aspecto subjetivo de un vinculo voluntario y moralmente justificado, una relación determinada objetivamente por la distribución desigual de los recursos entre los individuos" (Briquet, 2009: 9), introduce una relación de obligación a largo plazo. El obsequio de utensilios de cocina es un medio de extender las ramificaciones de esta “amistad", entre Willem y el ingeniero, a toda la Oepiap, a través de luchas internas por influencia. De hecho, Pedro, excluido de la Oepiap por Willem, creó su propia ONG para la cual contrató a estudiantes indígenas, incluido Luis, presidente de la Organización. Willem, que busca monopolizar el control de los canales de acceso a los recursos, alienta a Luis a reorientarse hacia una colaboración con Jorge en lugar de con su rival. "Como Jorge es mi amigo, quiere aprender mi idioma, el awajún. Él quiere pagar por ello. Busqué a alguien de la Oepiap: Luis. Quiero que [Luis] entienda que una vez que

25 Diario de campo.

26 Entrevista con Willem, expresidente de Oepiap y elegido estudiante regional de farmacia de 25 ańos, Iquitos, 6 de marzo de 2011. 
esté involucrado [en este servicio], al darle [a Jorge] toda la información necesaria [para llevar a cabo nuestros proyectos], la Oepiap continuará encontrando fondos. Especialmente quiero sacarlo [de la ONG de Pedro] y le diré 'Sabes qué, déjalo y trabaja. Diselo a Jorge, y él te pagará."27. Los cursos de awajún parecen ser un factor que favorece una colaboración más estrecha entre la Oepiap y la compañía de Jorge. Al facilitar esta relación, que proporcionará acceso a nuevos recursos para la Organización, Willem espera mantener su influencia sobre la Oepiap. Tales luchas internas dentro de la Organización facilitan así la formación de relaciones de cooperación con el sector económico. Luis enseña awajún a Jorge todos los días de 7 p. m. a 9 p. m. Este último se queda después de sus clases, invita a los cincuenta estudiantes a cenar varias veces y aprovecha la oportunidad para enviarles sus recomendaciones. El "amigo" tiene la oportunidad de guiar y autoridad para juzgar. Al enfatizar los valores de "humildad" y "apertura”, llama a los estudiantes a buscar alianzas y a involucrarse en el diálogo. Sin embargo, este discurso de "apertura" y "confianza" que acompaña a la ritualización de la amistad actúa como un mecanismo que califica ciertos comportamientos y descalifica a otros. Si bien abrirse es mostrar discernimiento, cerrarse y rechazar las ideas aportadas por los interlocutores externos es oponerse al progreso de la Organización. Con la constitución de estas "amistades paradójicas", se establecen jerarquías y criterios de juicio de acuerdo con la buena voluntad de los actores y su disposición al diálogo. Poco a poco, las prácticas de los estudiantes se reformulan: los "guerreros" que aparecían en los medios se vuelven profesionales de la mediación. Los beneficios resultantes tienen un carácter decisivo: más allá de los "obsequios" ocasionales, principalmente del sector extractivo, la cuenta bancaria de la Oepiap ha sido incrementada desde 2010 con una contribución de 10000 soles, pagados cada mes por T., una empresa petrolera canadiense que opera en la región ${ }^{28}$.

27 Entrevista con Willem, citada.

28 Esta cantidad es mencionada por los estudiantes y aparece en la tesorería interna de la Oepiap. Según el presidente de 2012 (que es el hermano mayor de Willem), esta es la única fuente de financiación para la Organización, aparte del apoyo puntual e individual de estudiantes que James, presidente de la RAL, solicita a familias británicas y polacas (Diario de campo, Iquitos, 18 de junio de 2012). 


\section{La "madurez política": reformulación de los principios de acción colectiva}

Elegido representante regional en la lista de un pequeño partido local desde septiembre de 2010, Willem trabajó anteriormente durante tres años en el PST. En el momento de nuestra reunión, en junio de 2010, criticó a los líderes indígenas que acordaron dialogar con el estado y dijo que habría que desconfiar de las negociaciones e involucrarse principalmente en la movilización ${ }^{29}$. Seis meses después de su elección al consejo regional, admite haber cambiado de opinión: "Los parámetros legales importantes han cambiado. T. es una empresa (petrolera) con un indice de responsabilidad social muy alto. Hablan sobre el calentamiento global, la responsabilidad social y ambiental. ;Pero los lideres no lo saben, porque nunca se toman el tiempo para discutir! Nosotros estamos discutiendo"30. Willem critica la posición de Aidesep, que se pliega a un rechazo total a la explotación de hidrocarburos:

"[Ellos] todavía dicen ;no queremos compañias petroleras, porque contaminan nuestras tierras!". Este el lenguaje común. Pero todo esto desaparecerá, ya lo verás. Poco a poco, se darán cuenta de que esto ya no existe. Lo que existe son altos índices y parámetros de control, ¿quiénes están aislados? [...] El problema no son las compañias petroleras y los extranjeros. ;El problema son nuestras propias leyes! Simplemente necesitamos un proceso de formalización. [...] Ahora tengo perspectivas para el Congreso [de la República]; Quiero crear una fuerte corriente indigena!

Willem y su organización se diferencian del "lenguaje común" al acordar "discutir" con las compañías petroleras. Afirman que solo así se puede entender que la negativa inflexible ya no es necesaria, porque los "índices de responsabilidad social" y los "parámetros legales" han cambiado las modalidades de extracción de petróleo. Se presentan como la vanguardia de un nuevo "movimiento indígena", cuya tarea será

29 Conversación informal, viaje entre Iquitos y Yurimaguas, 24 de junio de 2010.

30 Entrevista con Willem, citado. 
"formalizar" e implementar leyes claras para mejorar las condiciones de vida de los pueblos indígenas, mientras que Aidesep está obligada a permanecer aislada de este proceso, encerrada en el registro único de la protesta.

La Oepiap es el espacio de socialización para este "buen" tipo de liderazgo técnico y legalista, cuya reformulación influye en la forma en que los jóvenes indígenas conciben la acción colectiva. Uno de los principales "amigos" de la Organización, James, presidente de la RAL que alberga a los estudiantes, aprecia el "progreso" colectivo de estos: "El grupo ha madurado, entendiendo que su papel politico, en lugar de ser un papel de protesta, era establecer ciertas metas, ganar espacios [...] Protestar para ganar solo cinco lugares en el refectorio es relativamente fácil. Pero tener como proyecto politico ganar más espacio en la universidad, tener una mejor organización, buscar aliados, es mucho más que un mero acto de protesta" 31. El "papel político" que resulta de este proceso de maduración consiste en insertarse en un espacio de alianzas: la protesta es una primera etapa que debe dar paso a la verdadera política, a la creación de redes y la negociación. Las movilizaciones en las que participa la Oepiap son frecuentes, pero prevalece su dimensión simbólica. Se trata de "ganar espacios", de establecer una legitimidad para luego negociar con las autoridades regionales o universitarias. Con ello, la Organización puede atraer el interés de interlocutores estratégicos, crear y mantener alianzas que garanticen su supervivencia. Estos momentos visibles de protesta sustentan una actividad de "gestión" 32 permanente, que es la base de la acción colectiva de los estudiantes indígenas. El objetivo principal es establecer proyectos para garantizar la visibilidad y, por lo tanto, la viabilidad de la Organización: la presentación de un programa para la radio regional, la creación de una escuela intercultural en cooperación con las autoridades judiciales locales o la publicación de una revista de la Oepiap financiada por el ingeniero Jorge son todas oportunidades, observadas durante mi

31 Entrevista con James, presidente de la Red Ambiental de Loreto (RAL), Iquitos, 23 de marzo de 2011.

32 Expresión recurrente en la descripción que los funcionarios de la Oepiap dan sobre su actividad. 
trabajo de campo, de obtener ingresos concretos. La inflexión de las prácticas de la Organización -desde la protesta radical hasta la discusión y la gestión de proyectos- obedece en principio a juicios que descalifican a quienes se desvían de estas reglas de acción. Durante mi trabajo de campo, me quedó claro que los estudiantes considerados demasiado intransigentes se exponían a sanciones: aquellos que buscan romper la alianza con James y critican en los medios locales su gestión oculta de los recursos de las compańías petroleras quedan excluidos de la Organización; quien critica a otro miembro de la Oepiap en una reunión abierta a "amigos" de la Organización, se queda sin uso de la palabra ${ }^{33}$. Estas lógicas de descalificación dan como resultado la evolución de las posiciones individuales de los estudiantes y las justificaciones que les dan: se presentan como posibles profesionales de la mediación. La duración relativamente larga de su afiliación, debido a la dificultad previamente mencionada por los estudiantes para llegar al final de sus estudios ${ }^{34}$, favorece la influencia de las prácticas de acción colectiva en las estrategias individuales. Cuando se les pregunta acerca de sus aspiraciones profesionales, casi siempre responden refiriéndose a los proyectos que desean implementar en el campo del desarrollo, la ecología o la gestión de los recursos naturales. De los 36 estudiantes que entrevisté, 13 dijeron que ya habían trabajado, la mayoría de ellos en el sector de hidrocarburos (4) y / o de ONG (6). Quienes han abandonado la universidad son, en la mayoría de los casos, funcionarios electos locales, fundadores o empleados de las ONG, con el objetivo de garantizar la mejora de los recursos naturales o el patrimonio cultural de su comunidad, o técnicos en los "servicios de relaciones comunitarias" de empresas petroleras. Valoran la dimensión "horizontal" y "flexible" de sus proyectos, ya sea que se relacionen con la representación política, el desarrollo económico o la preservación de la cultura indígena. En cualquier caso, ellos tienen las habilidades de mediadores indígenas que se adaptan a la diversidad de interlocutores que desean contactar en sus comunidades, sobre todo porque la multiplicación de los llamados

33 Diario de campo, Iquitos, 20 de marzo de 2011.

34 De los 25 estudiantes que han estado afiliados por más de un año y han respondido al cuestionario, 14 dijeron que habían dejado de estudiar al menos una vez. 
espacios "participativos", y la difusión de discursos sobre desarrollo sostenible y comunitario ("fórmula" que favorece la concesión entre intereses en conflicto) (Krieg-Planque, 2010) fomentan la reunión de diferentes sectores en los que trabajan los estudiantes: representantes indígenas, autoridades locales y regionales, compañías petroleras, ONG ambientalistas. En caso de conflicto, estos jóvenes profesionales son intermediarios estratégicos que participan en el "gobierno de compromiso", legitimado dentro de sus comunidades nativas por su capital educativo, y a los ojos de los interlocutores externos por su representatividad. En este sentido, las carreras de los diversos miembros de la Oepiap evocan la tendencia a la "militancia institucional" de las organizaciones que, constituidas como colectivos de protesta, logran gestionar ciertos asuntos junto con las autoridades criticadas (Le Naour, 2005).

Como campo de análisis localizado, la Oepiap atestigua la pluralidad de "la gama de estrategias e interacciones que se desarrollan entre el polo de los dominantes y el de los dominados", y recuerda el interés de lo que está en juego "en esta área difusa y fluctuante, donde conviven los 'dominados de los dominantes' y los 'dominantes de los dominados'" (Dezalay \& Garth, 2002: 282). La protesta indígena no se reduce a la fuerte oposición que surgió durante las movilizaciones de 20082009. Si bien estos momentos de emoción son espacios importantes de socialización política y reflejan la fuerza de las propuestas de la protesta indígena, es eminentemente multifacética, como lo demuestra la vida cotidiana de los estudiantes indígenas. Sus prácticas pueden ser una crítica radical de los adversarios designados durante las movilizaciones, como también la formación de alianzas formales o informales con estos mismos adversarios.

Las "transacciones colusorias" en el origen de estas inflexiones solo se materializan a través de "constelaciones de intereses", una noción weberiana que permite, según Dobry, pensar en la dominación y los procesos de legitimación distintos de perspectiva vertical de los gobernantes hacia los gobernados (2003); incluso, si provienen de sectores diferentes y opuestos, los actores pueden ver, en un momento dado, que sus intereses convergen y se ponen en contacto. Esta perspectiva permite evitar 
lecturas en términos de "manipulación": la constitución de "amistades paradójicas" no elimina, sino que estimula la capacidad analítica de los estudiantes indígenas, que constantemente se preguntan acerca de las "intenciones" de sus interlocutores. Si bien la generalización de los discursos y las prácticas de "responsabilidad social corporativa" favorece las transacciones entre un número creciente de organizaciones indígenas en la Amazonía peruana y las compañías petroleras, estas tendencias nunca son lineales y están sujetas a la complejidad de diferentes áreas de disputa.

\section{Bibliografía}

Barclay, Frederica \& Fernando Santos-Granero, La frontera domesticada: historia económica y social de Loreto, 1850 -2000, Lima, Fondo Editorial PUCP, 2002.

Briquet, Jean-Louis. "Des amitiés paradoxales. Échanges intéressés et morale du désintéressement dans les relations de clientèle ", Politix, 12 (45), 2009.

Despic-Popovic, Hélène. "Coup de sang. Les Indiens du Pérou repartent en guerre", Libération, 8 juin 2009.

Dezalay, Yves \& Bryant G. Garth, "La mondialisation des guerres de palais. La restructuration du pouvoir d'État en Amérique latine entre notables du droit et "Chicago Boys" ", Paris, Le Seuil, 2002.

Dobry, Michael. "Légitimité et calcul rationnel. Remarques sur quelques "complications" de la sociologie de Max Weber", en Pierre Favre, Yves Schemeil, Jack Hayward, Etre gouverné. Études en l'honneur de Jean Leca, Paris, Presses de Sciences Po, 2003, pp. 127-147. 
Valeurs, croyances et transactions collusives. Notes pour une réorientation de l'analyse de la légitimation des systèmes démocratiques ", en: Javier Santiso (dir.), À la recherche de la démocratie. Mélanges offerts à Guy Hermet, Paris, Karthala, 2002.

Espinosa de Rivero, Oscar. "Ciudad e identidad cultural. ¿Cómo reubicarse con la economía urbana en el siglo XXI?", Boletín del Instituto Francés de Estudios Andinos, 38 (1), 2009.

"Para vivir mejor: los indígenas amazónicos y su acceso a la educación superior en el Perü". Revista ISEES (Inclusión e Igualdad en la Educación Superior), 2, 2008, pp. 87-116.

Hamidi, Camille. «Éléments pour une approche interactionniste de la politisation: engagement associatif et rapport au politique dans les associations locales issues de l'immigration ", Revue Française de Science Politique, 56 (1), 2006, pp. 5-25.

Hughes, Neil. "Indigenous Protest in Peru: The "Orchard Dog" Bites Back ", Social Movement Studies: Journal of Social, Cultural and Political Protest, 9 (1), 2010, pp. 85-90.

Krieg-Planque, Alice. "La formule "développement durable”: un opérateur de neutralisation de la conflictualité", Langage et société, 134 (4), 2010, pp. 5-29.

Le Naour, Gwenola. "Entrer dans l'action publique en la contestant. Quand la cause des usagers de drogues devient soluble dans la politique marseillaise de lutte contre le sida et la toxicomanie", Politix, 70, 2005, pp. 9-28. 
DORIS BUU-SAO

Nay, Oliver \& Andy Smith, «Les intermédiaires en politique. Médiations et jeux d'institutions", dans O. Nay, A. Smith (dir.), Le gouvernement du compromis : courtiers et généralistes dans l'action publique, Paris, Economica, 2002.

Poirier, Sylvie. "Les dynamiques relationnelles des jeunes autochtones ", dans Natacha Gagné, Laurent Jérôme (dir.), Jeunesses autochtones. Affirmation, innovation et résistance dans les mondes contemporains, Rennes, Presses universitaires de Rennes, 2009.

Redford, Kent H. "The Ecologically Noble Savage », Cultural Survival Quaterly, 15 (1), 1990, pp. 46-48. 